\title{
The Use of Coastal Reservoirs and SPP Strategy to Provide Sufficient High Quality Water to Coastal Communities
}

\author{
Shu-Qing Yang, Samuel Kelly \\ School of Civil, Mining and Environmental Engineering, University of Wollongong, Wollongong, Australia \\ Email: shuqing@uow.edu.au, fk587@uowmail.edu.au
}

Received 4 May 2015; accepted 10 July 2015; published 17 July 2015

\begin{abstract}
Water quality-induced water shortage is emerging as one of the main threats for the growth of the world's population and economic development, especially for coastal cities in developing nations. This paper discusses how to supply enough sufficiently clean water to such cities using the technologies of coastal reservoirs and wetland pre-treatments, as well as employing the SPP strategy. The so-called coastal reservoir is defined as a freshwater reservoir situated in seawater which sources its water from river runoff; to improve its water quality, a wetland is used to pre-treat the runoff that is potentially polluted by domestic, agricultural and industrial contaminants. Generally, the existing lakes in the urban-rural fringe are severely polluted; the Separation, Protection and Prevention (SPP) strategy can quickly restore the lakes' water quality to a drinkable standard. In this study, we take Shanghai, the largest city in China, as an example to investigate the feasibility of the proposed strategies. This investigation shows that using the technology of coastal reservoirs in Shanghai, namely the Qingcaosha Reservoir, freshwater can be pumped from the sea without requiring the desalination process and if an agricultural wetland on Chongming Island is used to pre-treat the river water prior to its storage, its water quality will be improved to Class II. It is also found that Dianshan Lake, which has been polluted and had a water quality of worse than class 5 in 2015, can have its water quality improved to class II in a short period if the SPP strategy is applied. It is expected that it will be a cost-effective and sustainable water supply method for coastal cities.
\end{abstract}

\section{Keywords}

Coastal Reservoir, Freshwater Water Supply, Dianshan Lake, Qingcaosha Reservoir, SPP Strategy

\section{Introduction}

The primary renewable source of freshwater on earth is continental rainfall, which generates a global supply of 40,000 - 45,000 $\mathrm{km}^{3}$ per year. This more or less a constant water supply that must support the entire world population, which is steadily increasing by approximately 85 million per year; thus the availability of freshwater per 
capita is decreasing rapidly. Currently about 80 countries and regions, representing $40 \%$ of the world's population, are experiencing water stress, and about 30 of these countries are suffering water scarcity during a large part of the year. During the last four decades, the number of countries experiencing water scarcity, most of which are developing countries, has increased. It is believed that by 2025, approximately 1.8 billion people will live in countries with absolute water scarcity (UN Water, 2013) [1]. To meet the crop demand projected for 2025, an additional 192 cubic miles of water per year could be required; a volume nearly equivalent to nearly 10 times the annual flow of the Nile (Gleick, 2001) [2]. Therefore a natural question to ask is: where will the water deficit become larger and larger and how should it be solved? In addition to the natural scarcity of freshwater in various regions and countries, the quality of the available freshwater is also deteriorating due to pollution, further intensifying this water shortage. Every day, 2 million tons of sewage and other effluents drain into the world's waterways, which is six times more water than already exists in all the rivers of the world. Presently, global water resources are grossly polluted by wastes to the point that vast stretches of rivers are dead or dying, and many lakes are cesspools of waste. Many options have been proposed worldwide to address the water supply issue, such as more inland reservoirs, desalination plants, wastewater reuse facilities etc.

Figure 1 shows the world's dam construction over the past 100 years and it is clear that after 2000 there were almost no new large new dams constructed; more and more people have realised the significance of a dam's negative impacts on the ecosystem, and no more suitable dam sites are left after the intensive construction of dams in the 20th century. A concrete dam's design life span is about 100 - 200 years; however the life span of such reservoirs also depends on their sedimentation rate. The total sediment yield worldwide is estimated to be $13.5 \times 109$ tonnes/a, or 150 tonnes $/ \mathrm{km}^{2}$, and about $25 \%$ of this is transported into the seas and oceans while the remaining $75 \%$ is trapped, retained and stored in the lakes, reservoirs and river systems (Batuca and Jordaan, 2000) [3]. Consequently the silting process is reducing the storage capacity of the world's reservoirs by more than $1 \%-1.5 \%$ per year, and in the world 300 - 400 new dams would need to be constructed every year to maintain the current total storage (White, 2001) [4]; all of the existing reservoirs shown in Figure 1 will be out of service by the end of the 21st century.

Figure 2 shows the percentage of people living in coastal areas. It can be seen that in Australia, 70\% of people lived in the coastal areas in the 1950s, but by 2050, this percentage is expected to increase to $92 \%$. Similar tendencies can be seen in the distribution of world population; in 1950 only $30 \%$ of total population lived in coastal regions, but by 2050, this will change to about $70 \%$. This is understandable because the coastal and deltaic areas are the most productive areas in the world. Will the strategy of utilising desalination plants or wastewater reuse dominate water supply for future populations when they are concentrated on the coast?

If the required energy and gas emission from these methods are calculated, surprisingly the findings show that these methods only serve to worsen the problems that they are attempting to solve, i.e., issues with sustainability and environmental impact. Table 1 shows the required energy and option sustainability if a medium sized city is supplied with $0.5 \times 109 \mathrm{~m}^{3}$ of water per year. It can be seen that a $500 \mathrm{GL} /$ year desalination plant will produce 3.33 million tons of carbon dioxide; equivalent to 2\% of the total CO2 emission from Shanghai in 2006 (=180 m tons).

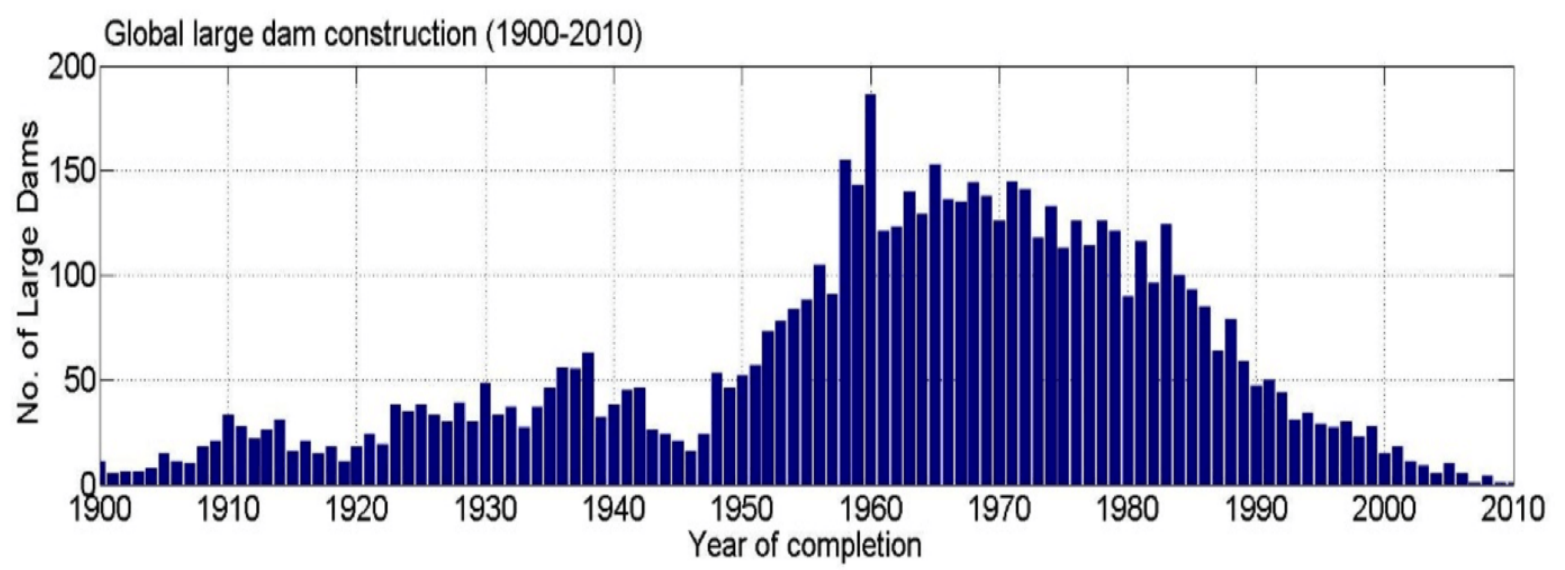

Figure 1. Global dam construction over the past 100 years, Source: Global Reservoir and Dam (GRanD) Database. 
Table 1. Comparison of different proposals to secure $0.5 \times 10^{9} \mathrm{~m}^{3} / \mathrm{yr}$ water in terms of sustainability, cost and $\mathrm{CO}_{2}$ emissions.

\begin{tabular}{|c|c|c|c|c|}
\hline & Inland dams & Desalination & $\begin{array}{c}\text { Recycled } \\
\text { wastewater }\end{array}$ & Coastal reservoir \\
\hline Energy used $\left(\times 10^{9} \mathrm{kWh}\right)$ & 0 & 2.0 & 1.0 & 0 \\
\hline $\begin{array}{l}\text { Green-house emission } \\
\mathrm{CO}_{2} \text { (million ton) }\end{array}$ & 0 & 3.33 & 1.67 & 0 \\
\hline $\begin{array}{l}\text { Construction cost } \\
\text { (billion \$AUD) }\end{array}$ & 11.42 & 9.28 & 10 & 2.8 \\
\hline $\begin{array}{l}\text { Maintenance/ } \\
\text { operation cost }\end{array}$ & Low & High & High & low \\
\hline Impacts on ecosystem & $\begin{array}{c}\text { Loss of } \\
\text { biodiversity }\end{array}$ & $\begin{array}{l}\text { Brine on marine } \\
\text { biodiversity. }\end{array}$ & Low & No negative impacts \\
\hline Life span & 100 & 20 years & 20 years & Infinite \\
\hline Sustainability & Permanent & $\begin{array}{l}\text { The damage on } \\
\text { ecosystem is remediable. }\end{array}$ & $\begin{array}{l}\text { No damage on the } \\
\text { ecosystem }\end{array}$ & Sustainable \\
\hline
\end{tabular}

Currently almost all of the world's water supply comes from inland reservoirs that are generally located in the remote upstream section of a catchment, but people on the other hand generally live in the lower/coastal regions of the catchment, leading to a mismatch between the water availability and the local water demand. To provide enough freshwater to the coastal areas, it is important to store water from runoff at the source. Therefore the most viable strategy is to build a fresh water dam in the sea, called a "coastal reservoir." Table 2 shows the existing coastal reservoirs in the world, and Table 3 shows the difference between inland reservoirs and coastal reservoirs. The main advantage of coastal reservoirs is that all runoff from a catchment can be fully collected if needed, and subsequently the reservoir can pump freshwater from the sea without requiring a desalination process.

\section{Background of Shanghai's Water Supply and Water Crisis}

Shanghai is situated in the delta of Yangtze River in the middle section of China's east coast. The total area of Greater Shanghai is $6340 \mathrm{~km}^{2}$ and the total population was more than 24 million in 2015. The municipality is bounded to west by Lake Tai, to the north by the Yangtze River and to the east by the East China Sea. The Yangtze River (Changjiang in Chinese) is the third-longest in the world, and it drains one-fifth of the country's total land area; a basin which is home to one-third of China's total population. Its average annual runoff is around $951.3 \times 10^{9} \mathrm{~m}^{3}$. Lake Tai is the third largest freshwater lake in China, having a surface area of $2238 \mathrm{~km}^{2}$ and containing $4.66 \times 10^{9} \mathrm{~m}^{3}$ of water (Yang and Liu 2010) [5], and on average its discharge makes up about $70 \%-80 \%$ of the Huangpu River, the mother river of Shanghai, flowing there via lakes and creeks such as Dianshan Lake, Taipu River and Suzhou Creek. The total water availability for Shanghai from the Yangtze and Lake Tai is about $962 \times 10^{9} \mathrm{~m}^{3}$. This is a strikingly water-rich city, surrounded with abundant water resources.

However, rapid deterioration of the water quality in the Huangpu River forces the shift of water supply from the Huangpu River to the Yangtze River, which now supplies about $70 \%-80 \%$ of water used by Shanghai; the remainder still comes from the Huangpu River. Currently, water consumption by the city of Shanghai for industrial, agricultural and domestic users is about 12 billion $\mathrm{m}^{3} /$ year. Of this water, only $1 / 5$ needs to be treated to the drinking standard, i.e., about 2.4 billion $\mathrm{m}^{3} /$ year in 2012. Figure 2 shows the general rising trend of population and water usage from 1977-2012. According to the government's plan to diversify its sources and to lower its risk for water supply, in the future the Huangpu River still needs to provide $20 \%$ - 30\% of tap water, i.e., 0.48 0.72 billion $\mathrm{m}^{3} /$ year; the remaining drinking water coming from the Qingcaosha coastal reservoir.

The main challenge for Shanghai's water crisis comes from the water quality of its two sources. The water quality of Huangpu River is continually degrading, all the way from its source at the Lake Tai to its lower reaches, including Dianshan Lake and the Taipu River, where the water is also polluted due to the rapid urbanisation and industrialisation (Che et al. 2005) [6]. In 2005, the water quality of Dianshan Lake was worse than class V, according to the Chinese Surface Water Standard; therefore the water cannot be used for any purpose. The Huangpu River is a multi-functional river that is used for drinking water, shipping, fishery, flood discharge, 
Table 2. Recently constructed coastal reservoirs in Asia.

\begin{tabular}{cccccc}
\hline Name & Catchment $\left(\mathrm{km}^{2}\right)$ & $\begin{array}{c}\text { Dam } \\
\text { length }(\mathrm{m})\end{array}$ & $\begin{array}{c}\text { Capacity } \\
\left(\text { million } \mathrm{m}^{3}\right)\end{array}$ & $\begin{array}{c}\text { Year } \\
\text { completed }\end{array}$ & Country/River \\
\hline Qingcaosha/Shanghai & 1.8 million & 43,000 & 553 & 2010 & China/Yangtze \\
Saemanguem & 332 & 33,000 & 530 & 2011 & South Korea \\
Sihwa & & 12,400 & 323 & 1994 & South Korea \\
Marina Barrage & 113 & 350 & & 2008 & Singapore \\
Chenhang/Shanghai & 1.8 million & 4700 & 8.3 & 1992 & China/Yangtze \\
Yu Huan/Zhejiang & 166 & 1080 & 64.1 & 1998 & China \\
Baogang/Shanghai & 1.8 million & & 12 & 1985 & China/Yangtze \\
Plover Cove & 45.9 & 2000 & 230 & 1968 & Hong Kong \\
\hline
\end{tabular}

Table 3. Differences between coastal and inland reservoirs.

\begin{tabular}{ccc}
\hline & Inland Reservoir & Coastal Reservoir \\
\hline Dam-site & Limited (mountainous area) & $\begin{array}{c}\text { Unlimited } \\
\text { (inside/outside } \\
\text { river mouth) } \\
\text { Dam design }\end{array}$ \\
Seepage & High pressure & $\begin{array}{c}\text { Low pressure but } \\
\text { with wave/tidal surge }\end{array}$ \\
Pollutants & By pressure difference & By density difference \\
Resettlement costs & Land based & Land based + seawater \\
Water supply & High & None \\
Water catchment & By gravity & By pump \\
\end{tabular}

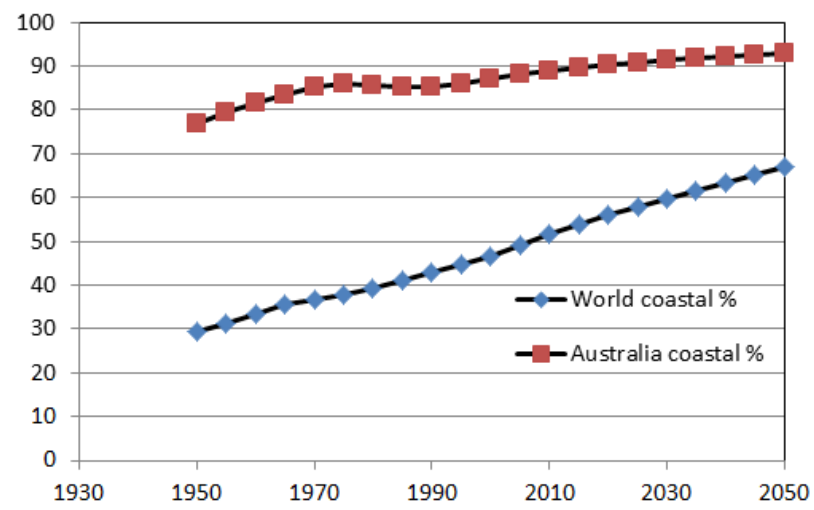

Figure 2. Percentage of population living on the coast in Australia and Worldwide.

tourism and many other functions. Any sudden water pollution accidents can incur a great risk and cause public panic; for example in 2013, more than 52 tons of petrochemical oil were leaked into the river in January, and in March about 16,000 diseased pig carcasses were found in the river. Consequently, in 2014 the government decided to construct a new reservoir near Dianshan Lake to head off these risks. The reservoirs will be excavated to have a storage capacity of about 5 million $\cdot \mathrm{m}^{3}$ to supply about 5 million nearby residents at a flow rate of 3.5 million $\mathrm{m}^{3}$ /day.

Shanghai is notorious for its pollution induced water crisis. Shanghai's water crisis has long been foreseen by the international community; for example, in 1996 a conference organised by the UN Center for Human Settle- 
ments (UN-Habitat) predicted that Shanghai would be one of the dozen cities with the most severe water crisis worldwide (N'Dow 1996) [7]. Shanghai's government has always been open to external experts' opinions and suggestions, and the author was lucky enough to be invited to offer suggestions in 2005. The authors' proposal is shown in Figure 3(c), and the main idea of the proposal was to pump the river water from the head of Chongming Island, followed by the river water being pre-treated by the agricultural wetland in Chongming Island, before finally storing the treated water in a coastal reservoir located at the northern side of Chongming Island; the details can be found from the online paper: 发展海洋水库是解决上海缺水问题的根本出路 (Coastal reservoir is the only feasible way to solve Shanghai water crisis) at http://www.docin.com/p-81001831.html.

Unfortunately in 2006 the author was told that the government had decided to construct a coastal reservoir, Qingcaosha, at a place different from where the author had suggested. Immediately the author gave his comments to the senior officer of water authority, with concerns pertaining to three aspects of water in this location; the flow could be too much, too little and too dirty:

1) The Qingcaosha Reservoir is located in the main flood passage of the estuary. If a 1000-year return flood (e.g., like the 1970 flood) occurs in the Yangtze River, the coastal reservoir along with whole of Changxin Island, upon which it is constructed, may be flushed into the sea. Furthermore, the drastic reduction of sediment supply from Yangtze River due to the construction of large dams (e.g. the Three Gorges Dam) would certainly lead to severe erosion at the estuary, rendering the Qingcaosha Reservoir unsafe due to heightened flood risk and lowered sediment supply.

2) Currently, the interface of freshwater and seawater moves up and down around the Qingcaosha reservoir. But the historical measurement data shows that in extreme dry years the interface moves upstream of coastal reservoir for a very long period of time. For example, the salinity in 1978-1979 at the mouth of the Huangpu River exceeded the drinkable limit for 102 days; however the Qingcaosha Reservoir can only supply 68 days of water without fresh intake. It is obvious that in an extremely dry year this reservoir may not be able to withdraw drinkable water, especially when other factors are considered, such as sea-level rise, the South-North Water Diversion Project, and the proposed schemes to enclose the Dongting and Poyang lakes upstream.

3) As shown in Figure 3(c), the reservoir is located at the point of intersection between the Yangtze River and the Huangpu River; the up and down tidal flow may eventually drive the wastewater generated in Shanghai into the reservoir. Figure 4 shows the steady growth of Shanghai population and water usage. Figure 5 shows the fertilizer and pesticide usage in the Yangtze River Basin, and its linear growth reveals that the quality of river water will be undrinkable. The author predicted that as a result of this contamination, algal blooms will be inevitable in the reservoir.

The above predictions have all been proven to be correct as algal blooms appeared in every year after the reservoir's completion in 2010. However, if the coastal reservoir had been constructed in the suggested area shown in Figure 5, then all the above problems should have been avoided, because: 1) the northern branch of Chongming Island is not the main flood passage, so it is a safe location in high floods and the reduction of sediment supply has little impact on its safety; 2) the intake is located $55 \mathrm{~km}$ further upstream relative to Qingcaosha's

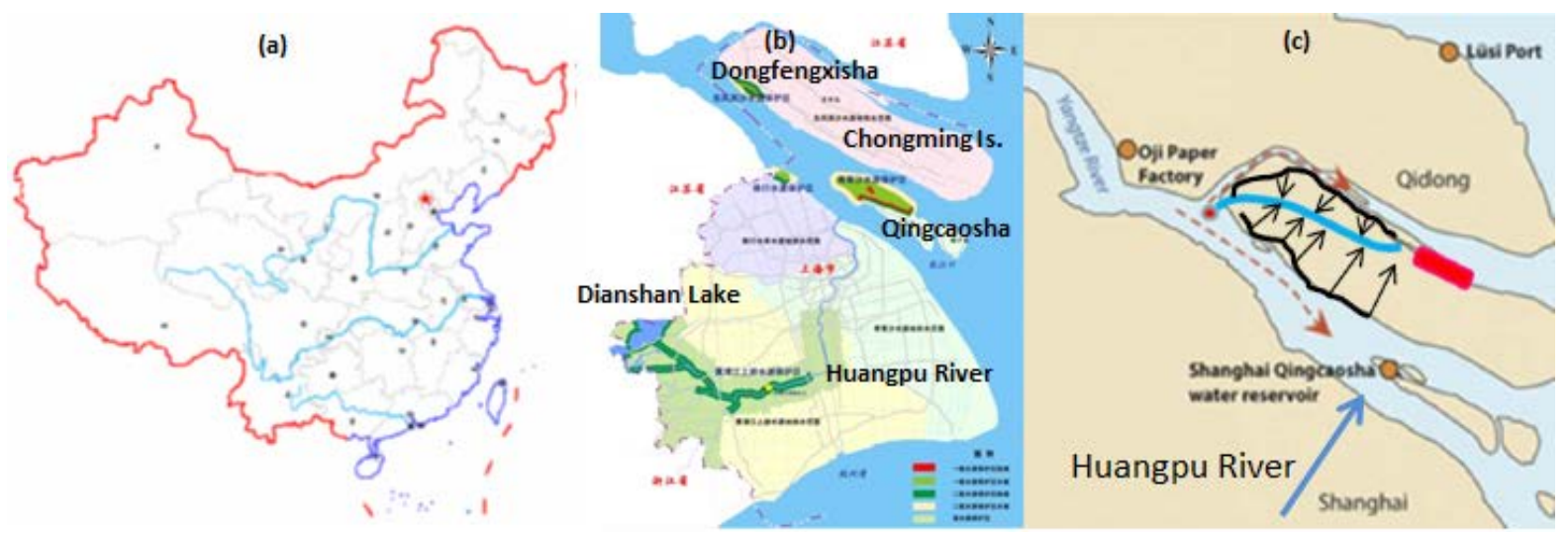

Figure 3. (a) China's main waterways; (b) Shanghai’s water networks; (c) Yang's 2005 proposal for Shanghai's water supply, with the intake at head of Chongming Island (red dot), the wetland pre-treatment (arrows) and the coastal reservoir storage (red block). 


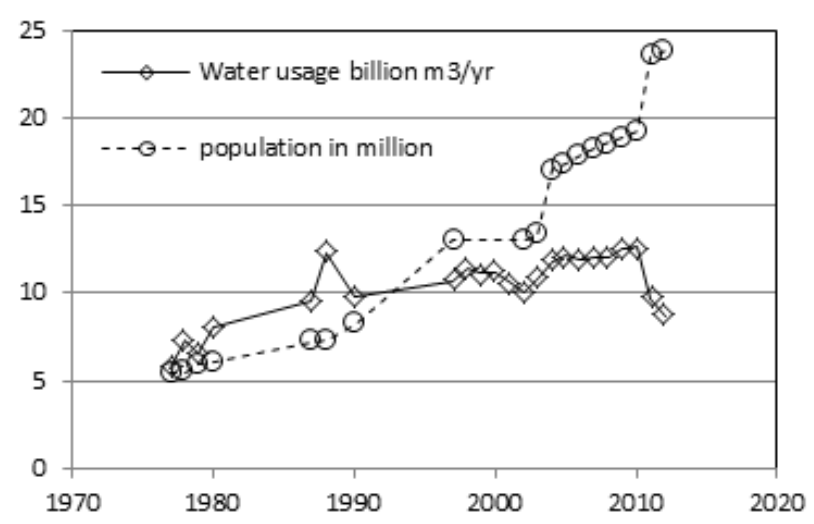

Figure 4. Total volume of freshwater used in Shanghai from $1977-2012$ (the data from 1981-1986, 1992-1996, and 19982002 are missed).

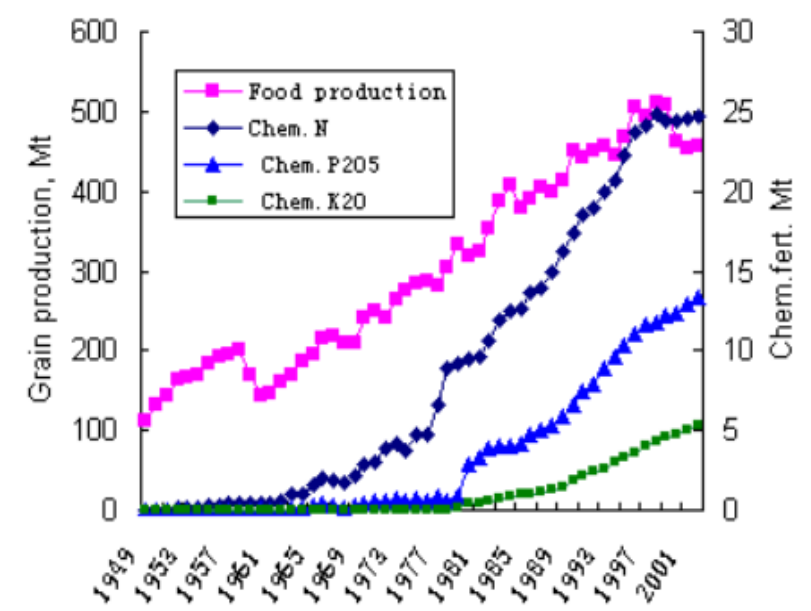

Figure 5. The usage of chemical fertiliser in the Yangtze River Basin and basin food production.

intake, so extreme droughts pose a minimal threat to its supply of freshwater; 3) the wetland pre-treatment can purify the polluted river water, assuring good quality water is stored. The feasibility of this will be analysed in the following section.

\section{Feasibility of Improving Qingcaosha Reservoir's Water Quality to Class II}

The author has reviewed all possible water supply methods in his book and concluded that coastal reservoirs will dominate future's water supply (Yang, 2004) [8], because:

1) Presently only use about $15 \%$ of the available water resources worldwide are being used, with the remaining $85 \%$ lost to the sea as floodwater. As the climate warms, some types of extreme weather could become more frequent and severe, and with increases in extreme heat comes intense precipitation, and long-term drought. Heavy rains and flooding may become more frequent. Change in weather patterns and runoff will require very large storage capacities that only the ocean can provide.

2) As more people migrate to coastal areas for permanent settlement, the existing water supply infrastructures cannot match the future distribution of the population. As a result of these changes, coastal areas will bear the highest water stress. Many Asian countries and cities have already experienced this change. For example in China, almost all coastal cities suffer severe water shortage.

3) Unlike conventional inland dams, coastal reservoirs collect runoff in a seawall-contained area in the ocean. Positioned at the end of a river mouth, it has the potential to capture all runoff from a watershed. Coastal reser- 
voirs provide the greatest potential for runoff collection. This innovative water solution has avoided the environmental impacts experienced by inland dams, such as the negative effects of the reservoir's downstream effluent, land inundation, and population displacement etc. Coastal reservoir construction costs are much less than conventional damming, and there are no energy costs, carbon emissions, desalination or treatment processes requires; unlike desalination plants and wastewater treatment plants.

As expected, recently a number of coastal reservoirs have been completed, including the Marina Barrage in the Singapore River and the Qingcaosha Reservoir in Yangtze River for Shanghai. A coastal reservoir is able to collect all of the runoff reaching the sea, but also captures all the pollutants generated in the catchment. Consequently, the water quality in the coastal reservoir may not be directly potable. Singapore is now using membrane technology to treat the water from its coastal reservoir. A significant challenge that future coastal reservoirs face is whether or not their water quality is comparable to that in the conventional dams, and if membrane treatment is necessary?

It is well known that wetlands are effective in removing impurities and the use of wetlands have become widespread in recent decades. Research has shown that wetlands are flexible systems that have been broadly integrated into water treatment due to their simplicity in application and operation and limited energy costs. Fisher and Acreman (2004) [9] analysed data from 57 constructed wetlands around the world and found that many of them have as much as a $90 \%$ nutrient reduction if it is appropriately designed. Currently, many constructed wetlands are used to treat a variety of wastewaters, but very few are used to treat large quantities of river water. Studies examining wetlands that intercept river water (Wu et al. 2011) [10] have shown that the maximum TN, NH4-N and TP removal efficiencies in summer could be up to $68 \%, 93 \%$ and $67 \%$, respectively. The research also shows that two factors may limit the application of wetland treatment at a large scale: the regular plantation and harvest of vegetation; and a very large wetland area required to obtain high efficiency in nutrient reduction. River water is often polluted by non-point source pollutants (e.g. fertilisers and pesticides used in agriculture) and point sources of pollution (urban and industrial wastewater). Any constructed wetlands have the potential to be unsuitable for coastal reservoir pre-treatment because coastal regions generally cannot provide a sufficient area to construct these wetlands. Maintenance of these wetlands is also a problem. Without the regular harvest of vegetation, wetlands can release large amounts of organic pollutants into the system at the times when dead vegetation is decomposing (during the winter). Experimental data shows that by removing dead vegetation, thus eliminating decomposition, effluent sediment concentrations and biological oxygen demand (BOD) can be reduced by $45.4 \%$ and $50.7 \%$, respectively, in comparison to non-harvested wetlands (Álvarez1 and Bécares, 2008). Most importantly, almost all research shows that winter nutrient removal efficiency in a wetland is much lower than during summer. This project aims to improve the design of wetlands used for this purpose.

In this paper, an innovative wetland (Figure 6) is proposal. This type of wetland uses eco-agricultural fields
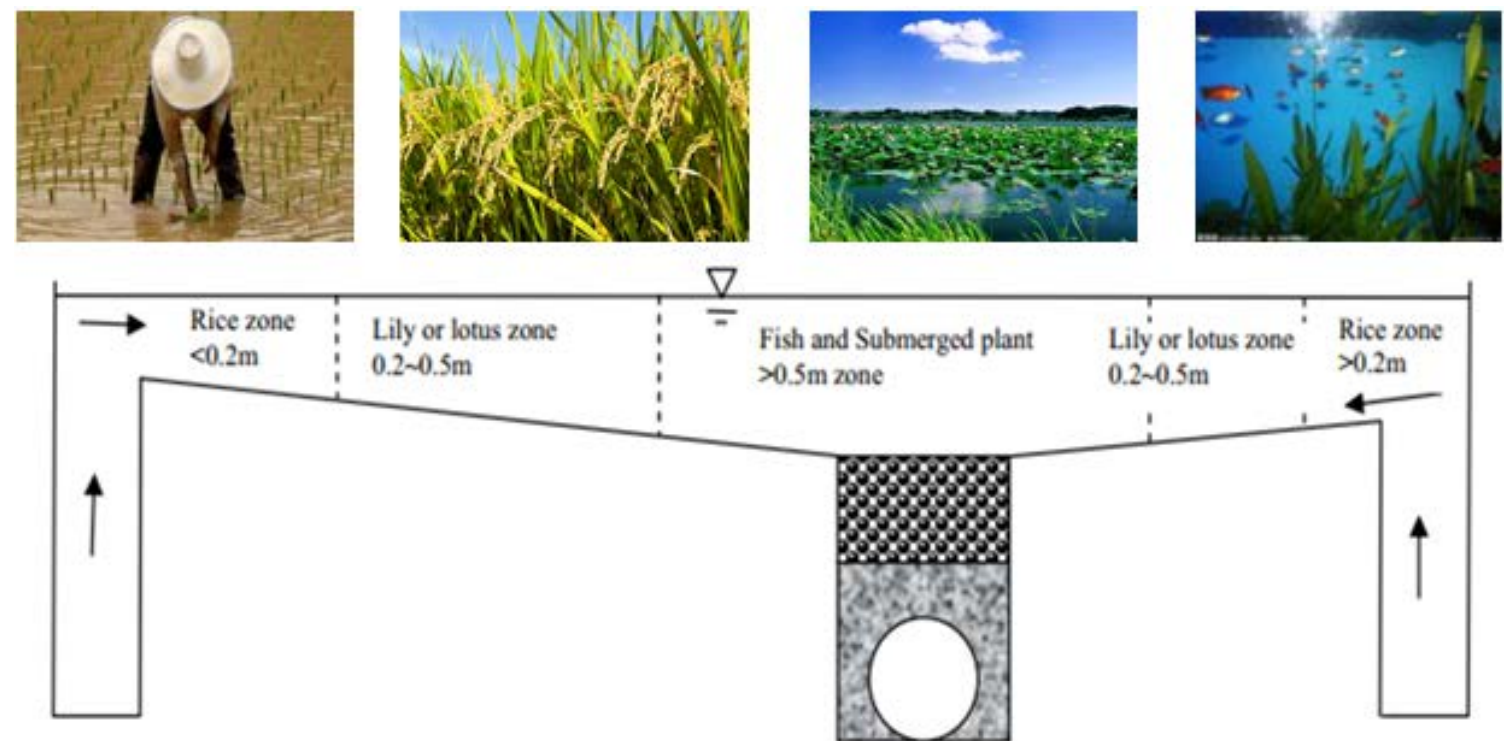

Figure 6. New wetland design to treat polluted river water for a coastal reservoir. 
as the wetland area to treat polluted river water. A study by Sukristiyonubowo, et al. (2012) [11] found that total nutrient removal through rice grains and straw ranged from 77 to $163 \mathrm{kgN}$ and 14 to $16 \mathrm{kgP}$ per hectare. Lawler (2001) [12] estimated that approximately $15 \%$ of the world's wetlands are rice fields or paddies. Rice fields are temporary wetlands combined with zones for lily and lotus plants and for fish and submerged plants. Deng's (2013) [13] research showed that growing lotus is effective for nutrient removal, resulting in the removal of at least $65 \%$ of the Chemical Oxygen Demand (COD), $70 \%$ of the nitrogen, $90 \%$ of the Suspended Solids (SS) and about $60 \%$ of the phosphorus. Fish are important in keeping the wetland in optimal condition; because they help with the purification process as they eat algae, and can even reduce mosquitoes and pests. Eco-agriculture (Figure 6) has been practiced for thousands of years, as it supports both agricultural production and biodiversity conservation. Working in harmony, they improve the livelihoods of rural communities. Remnants of excess fertilisers, pesticides and other nutrients are absorbed by agricultural wetlands even with no chemicals added. Water from the wetland is filtered through sand and/or gravels media into perforated pipes which remove water from the wetland system. Treated water is then transferred and stored in the coastal reservoir. The size of a coastal reservoir should be large enough to supply an adequate amount of water to the users during winter when the wetland cannot effectively treat the river water. In this study, the agricultural vegetation will also be examined. Our preliminary recommendation for Shanghai is shown in Figure 6. Types of native vegetation were chosen based on field trip to Chongming Island in Shanghai. The Shanghai government has identified Chongming Island as an eco-island, where no industry is allowed and eco-agricultural wetlands with no chemicals (similar to Figure 6) have emerged (http://www.mooyuufarm.com/index.html) and will be expanded by the Chinese Government on the $1041 \mathrm{~km}^{2}$ island. Hence, the types of wetland proposed for this location are feasible, and problems such as regular harvesting and plantation, wetland maintenance and the required large land area have been effectively dealt with.

\section{Feasibility to Remediate Polluted Lake to Potable Water in a Short Time-Dianshan Lake}

The inflows to a lake are the main sources of contamination during the dry period or first flushes after storms, but are also the main sources of clean water during wet periods. Therefore stormwater and polluted water appear at different times and the purpose of the SPP scheme is to separate the incoming water in time and space based on its water quality. The good quality water is stored in the lake by opening the water gates shown in Figure 7, and the polluted water will be forced to bypass and subsequently be discharged by closing the same water gates; thus the spatial separation based on quality can be achieved. The inner levees and gates can then be used to protect the clean water and the external pollution is prevented by the Bypass Pollution Canal (BPC). The inclusion

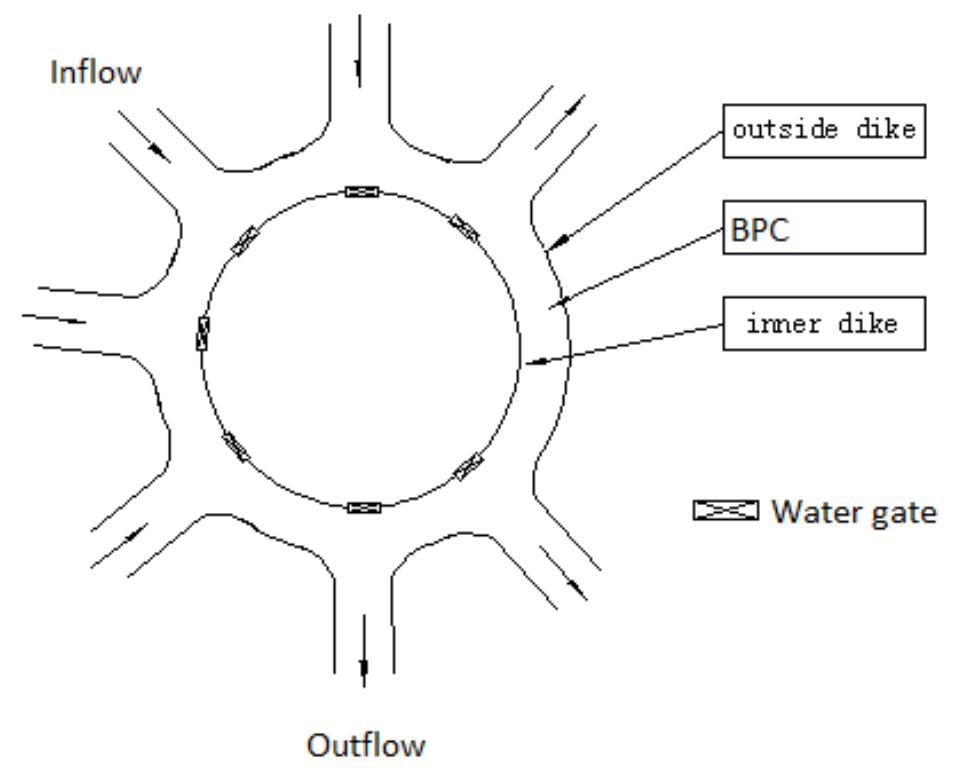

Figure 7. Bypass pollution canal (BPC) scheme in SPP strategy. 
of the BPC and its gates allows a high velocity to be maintained for the unwanted/polluted water in the BPC without it mixing with the clean water in the central area. In other words, the incoming water can be regulated by the gates and if the gates are opened, the lake is similar to the natural lake without SPP; once the gates are closed, the BPC actually becomes part of the river system, conveying the water with high velocity. Therefore, using an SPP strategy can develop clean water from a polluted river system where the water quality is unstable. It is worthwhile discussing whether or not this technology can transform Dianshan Lake into a clean water reservoir for Shanghai's water supply.

Dianshan Lake is the largest freshwater lake in Shanghai and connects with Huangpu River. Its surface area covers $63.8 \mathrm{~km}^{2}$ when the water level is $2.5 \mathrm{~m}$, its average depth $2.11 \mathrm{~m}$, and the highest water level was $3.71 \mathrm{~m}$ (August 1954) and the lowest was $1.76 \mathrm{~m}$ above the sea level (April 1963). The water level is also influenced by the tide (Cheng and Li, 2008) [14]. Dianshan Lake's residence time is about 29 days and its water velocity is $0.03-0.1 \mathrm{~m} / \mathrm{s}$. Annual rainfall here is about $1037 \mathrm{~mm}$ and annual evaporation is about $900 \mathrm{~mm}$. (Zhang and Zhang, 1992) [15]. In 1988, the annual runoff was about $1.74 \times 10^{9} \mathrm{~m}^{3}$, with about $67 \%$ of incoming water flowing from the Lake Tai via inlets such as Jishuigang (35\%) and Dazhuku (33\%); the Lanlugang outlet discharges about 71\% of outflow. Figure 8 shows the measured water quality data from 1984-2010 (Kang, 2012) [16]; the variation of TN and TP increases steadily from $1984(\mathrm{TP}=0.06 \mathrm{mg} / \mathrm{L}, \mathrm{TN}=0.83 \mathrm{mg} / \mathrm{L})$ to $2007(\mathrm{TP}=$ $0.237 \mathrm{mg} / \mathrm{L}, \mathrm{TN}=4.53 \mathrm{mg} / \mathrm{L}$ ). Consequently, 3 large scale algal blooms occurred in 2007 and 5 in 2008. Cheng and $\mathrm{Li}$ (2008) [14] found that the lake has been hyper-eutrophic since 1999. Researchers agree that the primary pollutants are nitrogen and phosphorus based substances, and TP is the controlling parameter for eutrophication in the lake.

Figure 9 shows Dianshan Lake, with the open dots with numbers representing measuring stations established
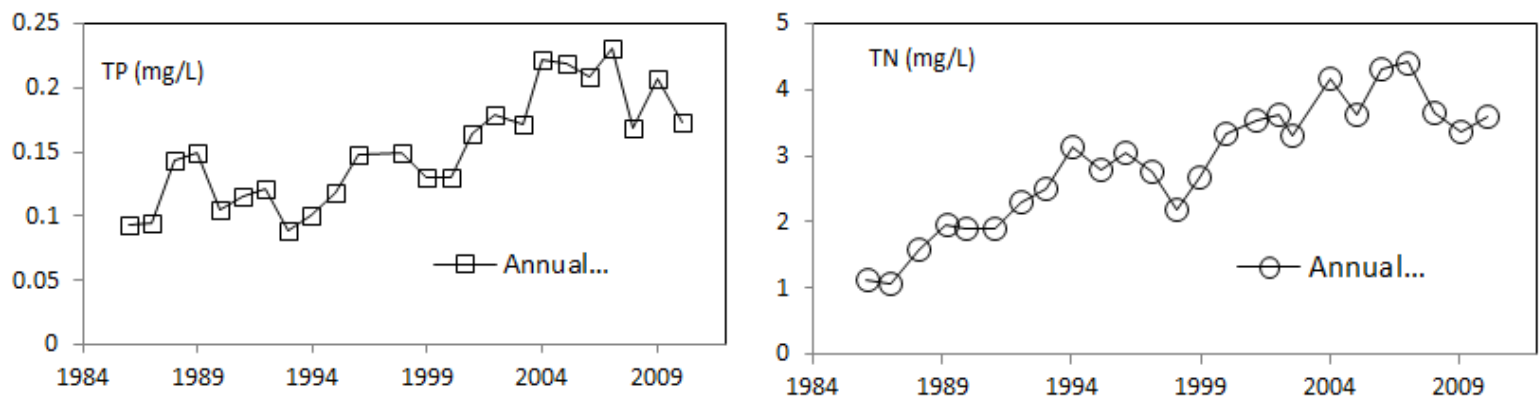

Figure 8. Variations of annual mean TP and TN in Dianshan Lake during 1986-2010.
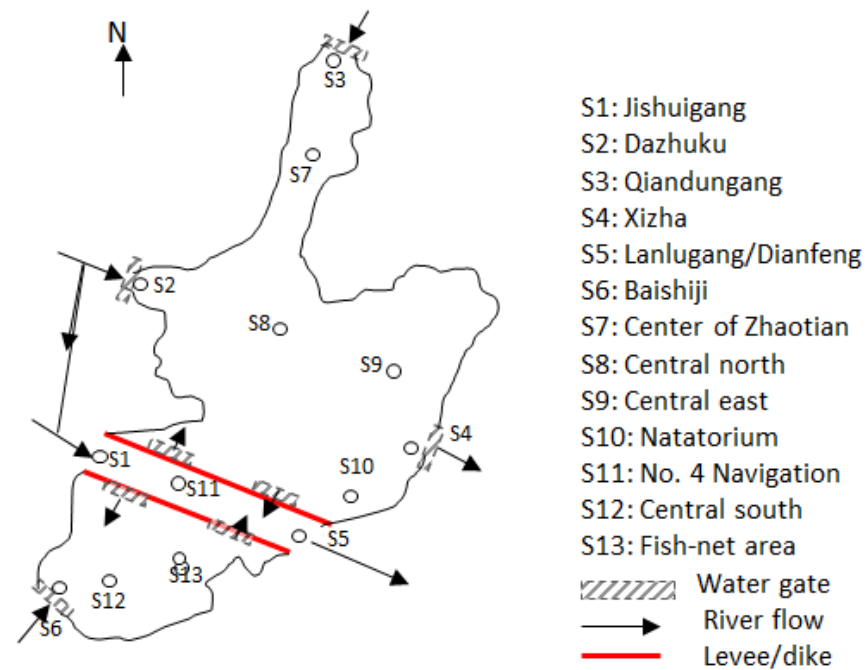

Figure 9. Dianshan Lake and its main inlets and outlet as well as the proposed SPP scheme, including BPC (between two red lines) and water gates (shaded bars). 
by the government to monitor the water quality and flow. The arrows denote the flow direction, the gates are represented by shadowed rectangular bars and the BPC, which diverts the heavily polluted water, is formed by red parallel lines. The BPC connects the Langlugang inlet and the Jishuigang outlet, which is a natural navigation channel. Although there are in total 59 interconnected rivers that connect with Dianshan Lake, 70\% - 80\% of incoming water comes from the Dazhugang and Jishuigang inlets; both rivers are interconnected via small lakes and creeks before water enters the Dianshan Lake and therefore if the Dazhugang gate is closed, the heavily polluted water will be forced to flow to the Jishuigang inlet and finally the contaminated water will be discharged out of the lake via the BPC and Langlugang.

To drive the water bodies into motion, two gates are proposed on each side of BPC levee, this may be helpful to limit algal blooms. If the gates at Qiandungang and Baishiji are closed, the heavily polluted water can flow to the downstream via the water networks. As a result, the purpose of protecting the clean water from external pollution can be achieved, and any sudden accidents like the dead pigs or chemical spills from ships will not affect the quality of drinking water.

The SPP scheme in Figure 9 includes the BPC which is about $150 \mathrm{~m}$ wide (the same as the upstream/ downstream navigation channel) and $6000 \mathrm{~m}$ long. It can be seen that with the BPC and water gates, the water quality can be secured and the lake may be transformed into an alternative water source for Shanghai. To confirm this, a series questions need to be answered: in the future, can the lake water meet Chinese government's standard for drinking water source, i.e., class I-III? As mentioned, in the future, about $0.48-0.72$ billion $\mathrm{m}^{3} /$ year of fresh water needs to be supplied to Shanghai from the Huangpu River; Dianshan Lake instead could supply about 1.0 billion $\mathrm{m}^{3} /$ year, thus it is sufficient to meet the water demand that is intended to be provided by the proposed "Water Source Lake (WSL)". According to its original design, the WSL's storage capacity is about 5 million $\mathrm{m}^{3}$, but Dianshan Lake's capacity is 148 million $\mathrm{m}^{3}$; about 30 times larger.

The water gates shown in Figure 9 may also be subject to some administrative difficulties as Dazhuku and Qiandungang are administrated by the Jangsu province, and not by Shanghai. If Jiangsu does not agree to construct the water gates, the author suggests constructing another levee along the border line between Shanghai and Jiangsu territories as shown in Figure 10. This way the polluted water can bypass the lake from its northern part via the Xizha outlet near S4. There are many ways to construct the required water gates; in this case the inflatable rubber dam alternative is highly recommended as this is a shallow lake and the small hydraulic head makes the rubber dam suitable for its operation and maintenance. The rubber dams can be inflated by pumping air or water into the rubber pipe, and deflation can be achieved by discharging the same air or water. The BPC can be formed when the rubber dam is inflated, but the BPC disappears when it is deflated.

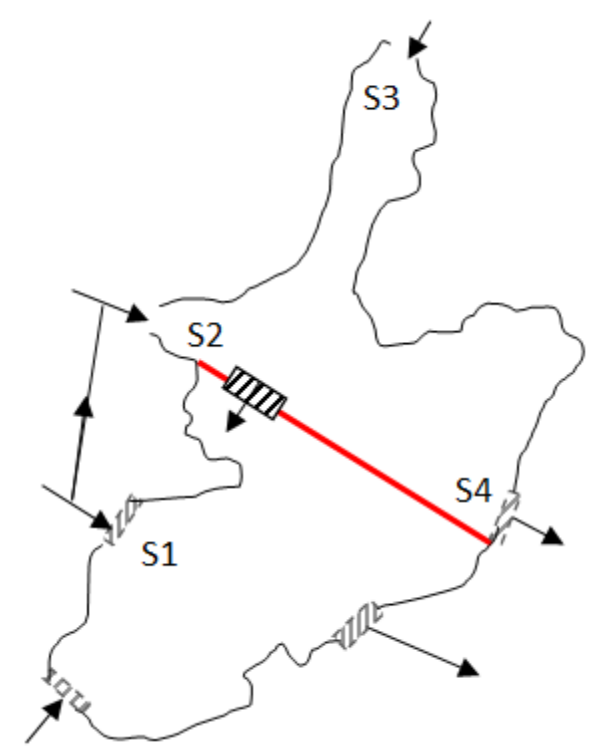

Figure 10. alternative SPP scheme in Dianshan Lake for the levee (red lines) and water gates (shadowed blocks); the polluted water at S1 will be discharged out of the lake at S4 via S2 together with the polluted water from S3. Clean water from $\mathrm{S} 2$ will be stored in the lake by opening the gate on the levee. 
It is worthwhile to justify the proposal using the recent data measured at the inlets and outlets, and at the southern and northern parts of the lake; which is shown in Figure 11 and Figure 12 for the period of 2011-2015. This data was measured and published by the Shanghai Environmental Protection Bureau on their website, and the Roman ordinate numbers represent the water class. Figures 11(a)-(b) clearly show that the water quality became worse in July 2014 when the first flush of typhoon stormwater entered the lake and mixed with the clean water; it leads to the water being class $\mathrm{V}+$. This is a typical event where the first flush pollutes the clean water in the lake, because currently the lake is an open water body and no actions can be taken to prevent the incoming pollution. Figure 10(a) also demonstrates that the incoming water quality is unstable, and good quality water always appears in S2 (Dazhuku) and S6 (Baishiqiao). The poor quality water mainly comes from S1 (Jishuigang) and S3 (Qiandongang). For these inlets, the clean water (class III) always appears July-October. Therefore, it is evident that the poor and good quality of water in the incoming river system changes intermittently, and the first flush is the source of pollution and must be discharged out of a lake. Figure 11(b) shows that the water quality in the outlets is much better than that of the incoming water; it implies that currently the Dianshan Lake receives poor quality water, but discharges comparatively good quality water downstream. The recent water quality data shown in Figures 11(a)-(b) indicate that the water of first flush should be discharged, rather than the good quality water and only utilising a SPP strategy can achieve this purpose.

This paper predicts that the lake can be developed as a source of drinking water if a SPP strategy is applied and a BPC is constructed. This conclusion is supported by the recent water quality data shown in Figure 11. In

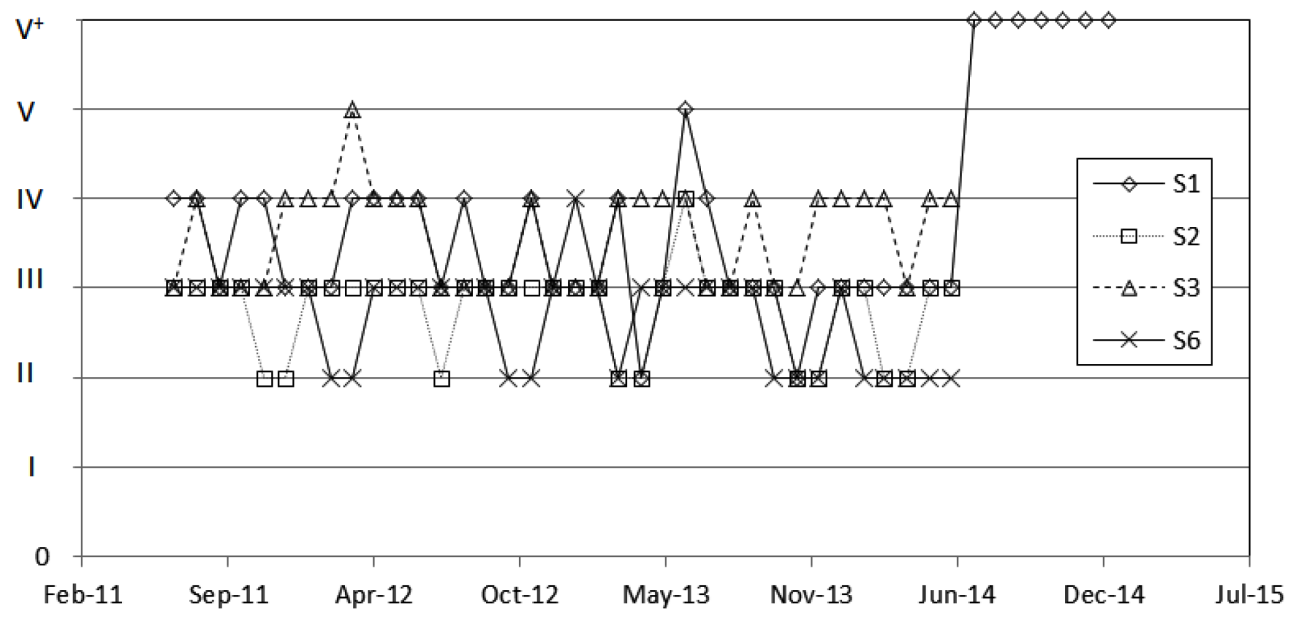

(a)

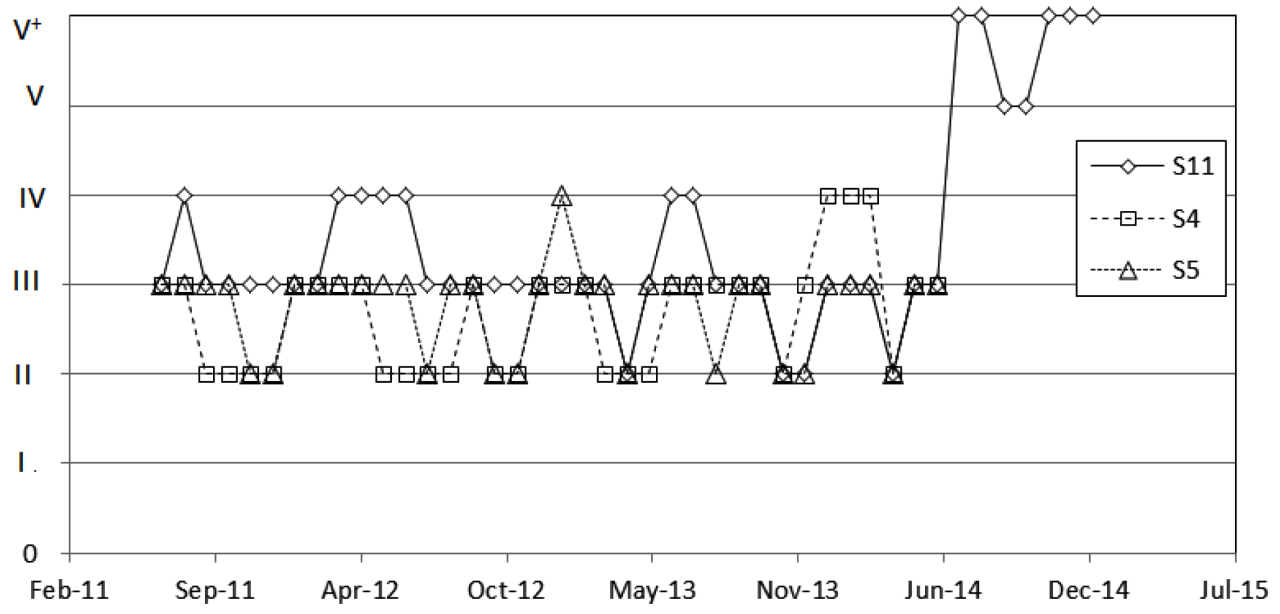

(b)

Figure 11. Measured water quality in Dianshan Lake's inlets (a) and outlets (b) for the period of 2011-2015. 


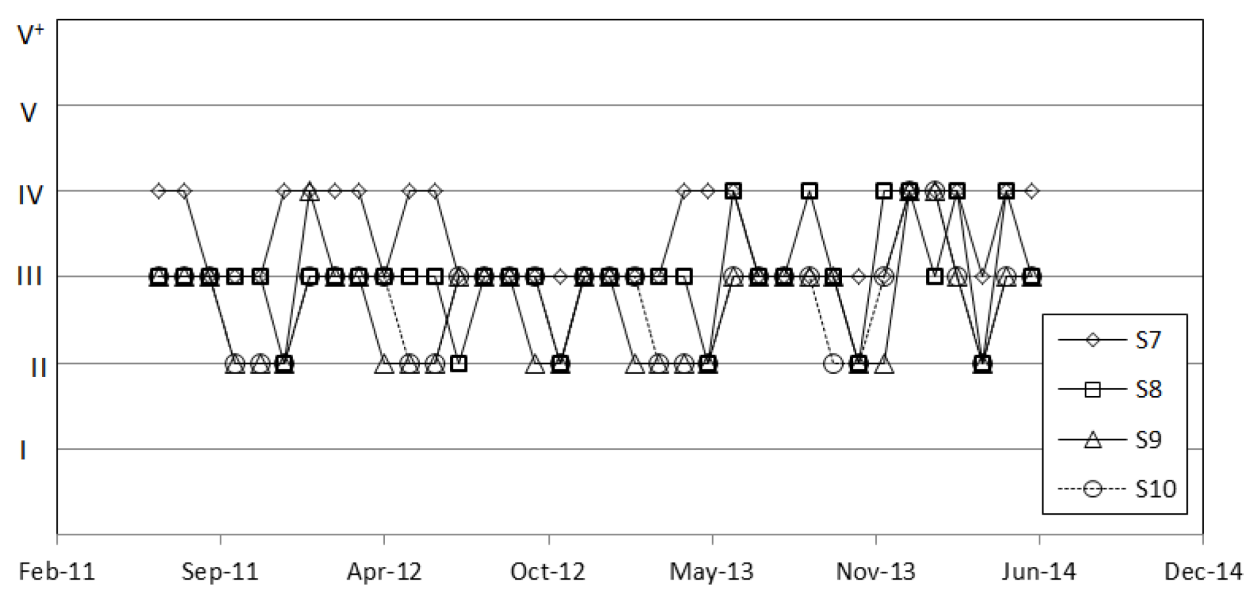

(a)

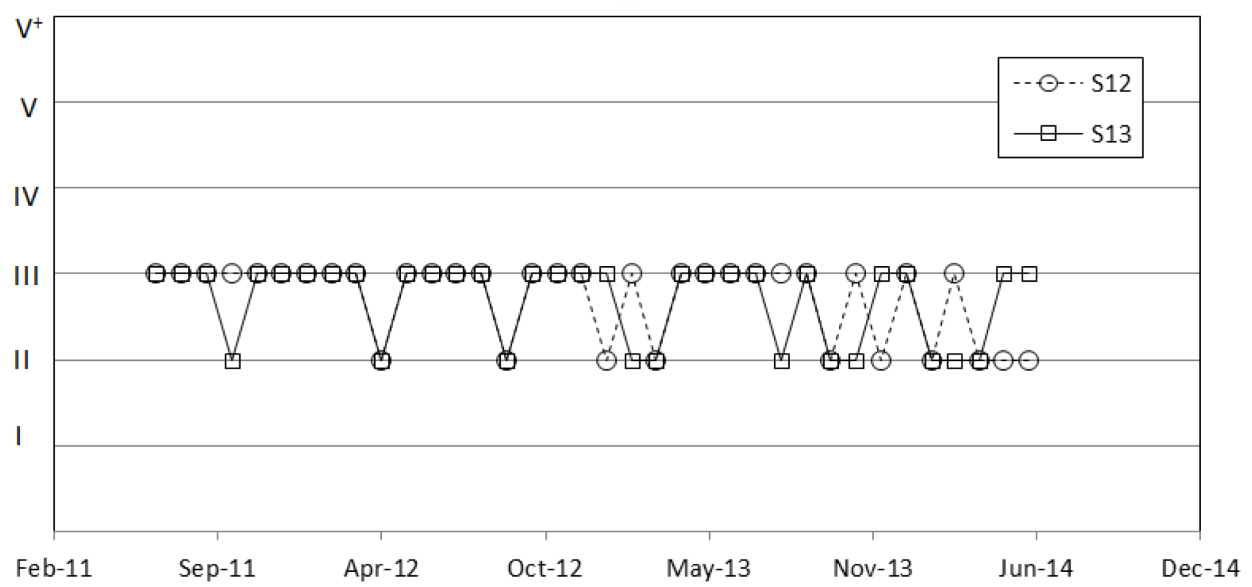

(b)

Figure 12. measured water quality in the northern (a) and southern (b) sections of Dianshan Lake 2011-2014.

Figure 9, the lake is divided into two parts by the proposed BPC, and the water quality in the northern part of the lake is shown in Figure 12(a) and southern part of the lake in Figure 12(b). It can be seen that from 20112014, the water quality in the southern lake meets fully the raw water standards for drinking water, i.e., class II and III in its natural condition. It can be predicted that the water quality will be improved further once SPP is applied as only water better than class III will be allowed to enter the protected southern lake.

The data in Figure 12(a) indicates that currently the water in the northern lake is not drinkable and from 2011-2014, the water quality is worse than the drinking water standard in 18 months; $50 \%$ of recorded time. Most of the poor quality water appears at S7 and S8, and relatively good water quality occurs at S9 and S10, where for only 4 months, or $11 \%$ of time, it cannot be used as drinking water.

Therefore, from Figure 11 and Figure 12, it is certain that Dianshan Lake could be transformed into a drinking water source if SPP is applied to prevent external pollution similar to what happened in July, 2014. The southern lake could immediately supply good quality water to Shanghai, but the northern lake would need a longer time to improve its water quality to drinking water standards. This means that for Shanghai it is unnecessary to excavate another new lake to secure its water supply, if the SPP strategy is applied.

\section{Conclusions}

This paper analysed the future population and water demand growth of Shanghai and its distribution, reviewed the existing water supply infrastructure and the following conclusions can be drawn:

1) In the next 100 years, the population and water demands may continue to increase significantly; most 
people in the future will live in coastal and deltaic areas.

2) The distribution of existing inland reservoirs will not match the population distribution in the future. The majority of the existing inland reservoirs will be out of service due to their structural life span and sedimentation.

3) The technology of the coastal reservoir is a sustainable, cost-effective and clean way for water supply, and it will dominate future water supply strategies. The water quality at river estuaries can be significantly improved by using agricultural wetlands. If Shanghai uses Chongming Island to pre-treat the water from the Yangtze, Shanghai's people can drink water with quality as good as the bottled spring water.

4) For a lake, the external pollution can be controlled once the unwanted water is discharged out of the lake; the remaining clean water can be developed for use as potable water. In other words, the polluted water will not mix with the lake water and its residence time in the lake will be very short; the clean water will become lake water and its residence time is very long.

5) If a SPP strategy is applied, Dianshan Lake's water quality will meet the Chinese Government's standard for drinking purposes (Class II or III). Conservative estimation shows that at least 1 billion $\cdot \mathrm{m}^{3}$ of clean water could be developed every year from the lake.

6) This study shows that SPP is effective for solving water quality-induced water shortage in water-rich areas. Compared to other methods to restore the polluted water bodies, SPP is more effective and straightforward as it prevents pollution mixing with the clean water; however more research is required in order to observe its effectiveness and performance.

\section{References}

[1] UN-Water (2013) Water Is Water Security? Infographic. United Nations Water. http://www.unwater.org/fileadmin/user-upload

[2] Gleick, P.H. (2001) Making Every Drop Count. Scientific American, 284, 41-45. http://dx.doi.org/10.1038/scientificamerican0201-40

[3] Batuca, D.G. and Jordaan, J.M. (2000) Silting and Desilting of Reservoirs. Balkema Publishers, Rotterdam.

[4] White, R. (2001) Evacuation of Sediments from Reservoirs. Thomas Telford Publishing, London. http://dx.doi.org/10.1680/eosfr.29538

[5] Yang, S.Q. and Liu, P.W. (2010) Strategy of Pollution Prevention in Taihu Lake and Its Effects Analysis. Journal of Great Lakes Research, 36, 150-158. http://dx.doi.org/10.1016/j.jglr.2009.12.010

[6] Che, Y., Yang, K., Wu, E. and Yuan, W. (2005) Water Supply Development Strategy and Source Water Area Protection in Shanghai: Patterns, Problems and Prospects. Journal of Natural Resources, 20, 651-658.

[7] N'Dow (1996) Water Crisis to Strike Most Developing World Cities by 2010 Istanbul: Habitat II.

[8] Yang, S.Q. (2004) Global and China's Water Crisis and Its Solutions in the 21st Century. Tianjin University Press.

[9] Fisher, J. and Acreman, M.C. (2004) Wetland Nutrient Removal: A Review of the Evidence. Hydrology and Earth System Science, 8, 673-685. http://dx.doi.org/10.5194/hess-8-673-2004

[10] Wu, H., Zhang, J., Li, P., Zhang, J., Xie, H. and Zhang, B. (2011) Nutrient Removal in Constructed Microcosm Wetlands for Treating Polluted River Water in Northern China. Ecological Engineering, 37, 560-568. http://dx.doi.org/10.1016/j.ecoleng.2010.11.020

[11] Sukristiyonubowo, Nugroho, K. and Vadari, T. (2012) Nutrient Removal by Rice Cultivated in Newly Opened Wetland Rice in Bulungan District, East Kalimantan. Journal of Tropical Soils, 17, 115-120.

[12] Lawler (2001)

[13] Deng, M. (2013) A Study about Water Treatment Efficiency in Lotus Wetland. Guangdong Agricultural Science, 18, 183-185.

[14] Cheng, X. and Li, X. (2008) 20-Year Variations of N and P and Their Impacts on the Algal Growth in Lake Dianshan, China. Journal of Lake Sciences, 20, 409-419.

[15] Zhang and Zhang (1992)

[16] Kang (2012) 